\title{
Factors affecting HIV counselling and testing among Ethiopian women aged 15- 49
}

\author{
Asfaw Negero Erena ${ }^{1,2^{*}}$, Guanxin Shen ${ }^{1}$ and Ping Lei ${ }^{1}$
}

\begin{abstract}
Background: HIV voluntary counseling and testing (VCT) is a crucial gateway to all strategies related to care, prevention and treatment of human immunodeficiency virus (HIV) infection. Nevertheless, utilization of voluntary counselling and testing (VCT) service among adults is very low in Ethiopia. The objective of this study is to identify determinants associated with VCT utilization among adult women aged 15-49 in Ethiopia.

Methods: A cross-sectional study was conducted based on data taken from the Ethiopian Demographic Health Survey (EDHS) 2016. Using cluster sampling, 14,369 women aged 15-49years were selected from all the nine administrative regions and two city administrations. Logistic regression was used to analyze factors associated with HIV VCT utilization.

Results: Overall prevalence of ever tested for HIV was 53\% (95\% Cl, 52, 54). Aged 20-44, ever married, being at higher socio economic position (SEP) and having risky sexual behavior were factors which are positively associated with VCT utilization. Being Muslims in urban and protestants in rural were factors significantly and negatively associated with VCT utilization. Those who had stigmatizing attitude both in urban and rural and who had comprehensive knowledge in rural were less likely to utilize VCT service.

Conclusion: VCT utilization among women in Ethiopia is demonstrating better improvement in recent years. However, stigmatizing attitude continued to be among the major factors, which are negatively affecting VCT uptake among women in Ethiopia. Concerted efforts should be made by all stakeholders to mitigate stigma, improve socio economic inequities and increase awareness on the benefit of VCT in controlling HIV in the society. In this aspect, the role of religious leader, schools, health extension workers and community leaders should not be undermined.
\end{abstract}

\section{Background}

HIV testing is a cornerstone for all HIV prevention strategies and been promoted as an important first step strategy to detect, treat, and prevent human immunodeficiency virus (HIV) infection. But unfortunately more than half of the people living with HIV do not know their sero-status [1-3]. Successful HIV prevention is largely depending on improved HIV testing technology and HIV testing practice in the community. Hence, HIV voluntary counselling and testing (VCT) is a gateway to all systems of AIDS-related care [3, 4]. According to the

\footnotetext{
* Correspondence: asfneg@yahoo.com

1Department of Immunology, School of Basic Medicine, Tongji Medical College, Huazhong University of Science and Technology, Wuhan, China ${ }^{2}$ Madawalabu University, College of Medicine and Health Sciences, Bale Goba, Ethiopia
}

United States Center for Disease Control and Prevention (CDC) recommendation, HIV screening should be done for all patients aged 13 to 64 years in all health care settings, including hospital emergency departments, urgent care clinics, inpatient services, sexually transmitted disease clinics, tuberculosis clinics, and primary care offices after informed consent is obtained $[5,6]$.

Legal, policy and social barriers continued to restrict individuals access to HIV care services and HIV testing remains infrequent regardless of its pivotal role in controlling HIV epidemic [7, 8]. Almost all countries are still far from realization of United Nation's Joint program HIV/AIDS (UNAIDS) plan to end AIDS epidemic by 2030 and achieving $90 \%$ diagnosis for all HIV infected individuals by 2020. According to data analyzed from Demographic and Health survey of 15 sub-Saharan 
Africa, 23 to $71 \%$ of people living with HIV knows their sero-status. Similarly systematic data analysis of national HIV treatment from 69 countries showed that HIV diagnosis (target one-90\% of all HIV-positive people diagnosed) varied from $87 \%$ (the Netherlands) to $11 \%$ in Yemen [9-11].

Even though women are at higher risk for HIV acquisition and the prevalence of HIV among adults in SubSaharan Africa is enormously high, women's access to HIV testing is uneven and HIV testing and counseling uptake among women remains at its low level [12-14]. Especially adolescent girls and women bear disproportionate HIV burden accounting for two out of three new infection occurring each day globally [15].

Ethiopia has also been implementing HIV voluntary counselling and testing (VCT) as a key strategy in its effort to prevent and control HIV/AIDS in the country. However, the utilization of VCT service among males, females, adults and people living in rural areas of the country is still low $[16,17]$. According to Ethiopia Federal Ministry of Health (2007) report, women are particularly vulnerable to HIV infection and face multiple challenges in making decisions concerning their reproductive lives. Therefore, counselling is an important tool to empower women to make informed decisions that would help them prevent HIV infection (Federal HIV/ AIDS Prevention and Control Office Federal Ministry of Health July 2007).

Understanding determinant factors affecting utilization of VCT helps policy makers in an effort to design effective strategies toward preventing and control of HIV/ ADIS including improving the uptake of VCT in general public and among women specifically. In Ethiopia information on factors determining HIV testing among women is not sufficiently available. The current study aimed at identifying underline factor preventing women aged 15-49 from utilizing VCT.

\section{Methods}

\section{Data source}

This study used secondary data collected by 2016 Ethiopian Demographic Health Survey (EDHS). EDHS 2016 is nationally representative and the most recent national survey on HIV testing. The Ethiopian Central Statistical Agency (ECSA) conducted the survey, with a technical assistance from Strategic consulting \& communications for a digital world/ICF International. Data were collected according to a standard protocol of Demographic and Health Survey (DHS), which had three core survey questionnaires; the Household Questionnaire, the Woman's Questionnaire and the Man's Questionnaire. These questionnaires were translated into three major languages of the country- Amharigna, Afan Oromo, and Tigrigna. The questionnaires were pretested in all three languages before the start of fieldwork and the properly trained interviewers interviewed respondents. ICF International staff and representatives from other organizations participated in fieldwork monitoring. A quality control team was present in each of 9 regions and 2 city administrations [18].

\section{Study population and sampling procedure}

The 2016 EDHS used a non-proportionate two-stage sampling design with stratification into urban and rural areas. At step one of the sampling, 645 clusters (202 urban and 443 rural) were selected on the basis of the 2007 Ethiopian population and housing census sampling frame [19]. The second phase of the sampling involved a complete listing of households in each selected cluster followed by a systematic random sampling of approximately 28 households from each cluster (giving a total of 18,008 households), of which 17,067 households were occupied and 14,369 out of 15,683 eligible participants were interviewed [19] (Fig. 1).

\section{Measurements}

The dependent variable for the study was HIV testing and it was measured by asking the question: 'Have you ever tested for HIV?'. The independent variables included socio-demographic characteristics: age, marital status, religion, residence, region, socio-economic position (SEP), HIV/AIDS-related knowledge, HIV/AIDSrelated stigma towards people living with HIV/AIDS, and risky sexual behavior.

\section{Operational definitions}

An index of the study participants' socio-economic position was developed based on their educational level, wealth index, and occupational status. Primarily, wealth index and occupational status sub-variable were grouped into three categories and educational level sub-variable was grouped into four categories and then added together. This summation index gave a value ranging from 2 to 9. Participants' SEP was categorized as low (score 2-5), middle (score 6-7), and high (score 8-9). Religion was categorized into five groups: Orthodox, Catholic, Protestant, Muslim and other. HIV/AIDS-related knowledge index was built from the answers to six questions: three questions on knowledge of HIV prevention and three on misconceptions about modes of HIV transmission. It was categorized as low (score $\leq 3$ ), high (score 45), or comprehensive (score 6) knowledge. To measure participant's risky sexual behavior history, participants were given five questions associated to their sexual behaviors (see Table 1) earlier to the survey. Having had any STI in last 12 months, having had genital sore/ulcer in last 12 months, having had genital discharge in last 12 months, having had at least one sexual partner other 


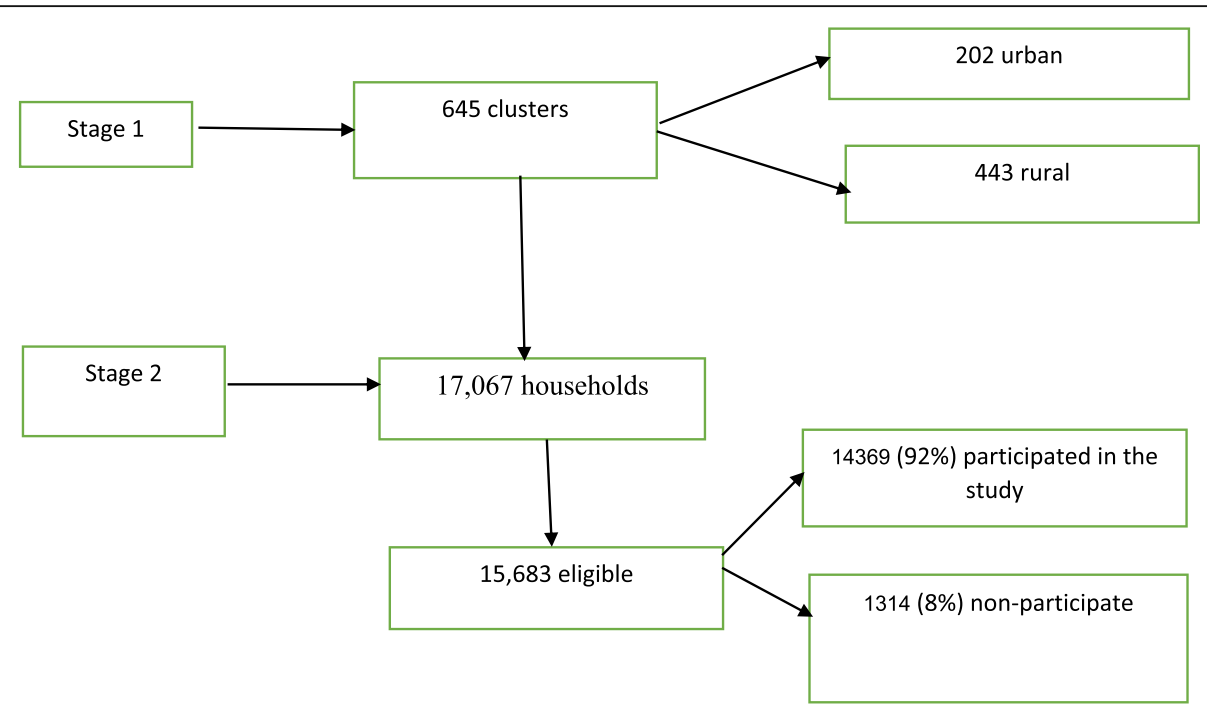

Fig. 1 Sampling procedure and participation rate

than husband in last 12 months, and having had multiple life time sexual partner were the questions asked to assess risky sexual behaviors of the participants. These were combined into an index of risky sexual behavior with three categories: "No risk" (score 0), "Some risk" (score 1) and "High risk" (score $\geq 2$ ). According to the Joint United Nations Programme on HIV/AIDS (UNAIDS, 2014) definition, HIV-related stigma refers to negative beliefs, feelings and attitudes towards people living with HIV, their families and people who work with them.

Six questions that reflected negative attitudes about people living with HIV/AIDS were used to create a stigma index. This index was categorized as "No stigma" (score 6), "Low stigma" (score 4-5), "Moderate stigma" (score 2-3), and "High stigma" (score $\leq 1$ ).

\section{Data analysis}

The data were analyzed using SPSS version 24. Logistic regression was used to assess the associations between the dependent and independent variables. In the regression models, information on age, marital status, SEP, religion, region, HIV/AIDS-related stigma, HIV/ AIDS-related knowledge, and risky sexual behavior history, were included as independent variables (see framework in Fig. 2).

The association between the dependent and each independent variable was analyzed using logistic regression analysis. A stepwise approach was employed in building the multivariate models. In the first model, the association between the socio-demographic variables and VCT was assessed. In the second model, both sociodemographic characteristics and more proximal determinants (HIV/AIDS-related knowledge and stigmatizing attitudes) were included. In the final model, all variables were included. The associations were presented as odds ratios (OR) and 95\% confidence intervals. The analysis was stratified by residence (urban and rural) due to interaction.

\section{Results}

Back ground characteristics and HIV testing history

The mean age of the participants was 28 years and $59.4 \%$ in urban and $79.4 \%$ in rural were married. Fifty two percent of women in urban were at middle socio economic position, but the majority of rural participants (83.1\%) were at lower socio economic position. Eighty percent of the study participants reported that they knew a place where they could get tested for HIV. Seventy three percent of urban and $41.6 \%$ of rural women had ever tested for HIV. Overall prevalence of ever having tested for HIV among women aged 15-49 was 53\% (95\% CI, 52, 45 ) and $93.1 \%$ of them who had tested had received result from last HIV test (Tables 1 and 2).

\section{HIV/AIDS-related knowledge}

The participant's knowledge on all specific measured parameters was higher among urban than among rural women both in terms of HIV prevention and means of transmission. About half of the participants in rural and $76.6 \%$ in urban knew that regular condom usage during sex reduce risk of getting HIV. Eighty six percent of women in urban and $80.6 \%$ of rural women were in low knowledge indicator category. Similarly, $53.6 \%$ rural and $31.5 \%$ urban women residents responded they still believe that they might get infected with HIV by mosquito bite and $41.2 \%$ of women living in rural didn't know the fact that healthy looking person can have HIV (Tables 1 and 2). 
Table 1 VCT uptake in relation to HIV/AIDS-related knowledge, HIV/AIDS-related stigma and risky sexual behavior history among Women in Ethiopia, 2016

\begin{tabular}{|c|c|c|c|c|}
\hline \multirow[t]{2}{*}{ Variables } & \multicolumn{2}{|l|}{ Urban } & \multicolumn{2}{|l|}{ Rural } \\
\hline & $N(\%)$ & Ever HIV tested (\%) & $n(\%)$ & Ever HIV tested (\%) \\
\hline Overall & $5232(36.4)$ & $3802(72.7)$ & $9137(63.6)$ & $3800(41.6)$ \\
\hline \multicolumn{5}{|l|}{ Knowledge Indicator } \\
\hline Reduce risk of getting HIV: always use condoms during sex (Yes) & 4009 (76.6) & $3066(58.6)$ & $4628(50.7)$ & $2356(25.8)$ \\
\hline $\begin{array}{l}\text { Reduce risk of getting HIV: have } 1 \text { sex partner only, who } \\
\text { has no other partners (Yes) }\end{array}$ & $4108(78.5)$ & $3069(58.7)$ & $6041(66.1)$ & $2748(30.1)$ \\
\hline Can get HIV from mosquito bites (No) & $3582(68.5)$ & $2660(50.8)$ & $4239(46.4)$ & $1972(21.6)$ \\
\hline Can get HIV by sharing food with person who has AIDS (No) & $4848(92.7)$ & $3582(68.5)$ & $6630(72.6)$ & $3169(34.7)$ \\
\hline Can get HIV by witchcraft or supernatural means (No) & $4773(91.2)$ & $3512(67.1)$ & $7011(76.7)$ & $3193(34.9)$ \\
\hline A healthy looking person can have HIV (Yes) & $3855(73.7)$ & $2898(55.4)$ & $5368(58.8)$ & $2556(28.0)$ \\
\hline \multicolumn{5}{|l|}{ Stigma Indicator } \\
\hline Would be ashamed if someone in the family had HIV (Disagree) & $4180(79.9)$ & $3140(60.0)$ & $4389(48)$ & $2109(23.1)$ \\
\hline Would buy vegetables from vendor with HIV (Yes) & $4106(78.5)$ & $3149(60.2)$ & $3199(35.0)$ & $1660(18.2)$ \\
\hline $\begin{array}{l}\text { Children with HIV should be allowed to attend school with } \\
\text { children without HIV (Yes) }\end{array}$ & $4168(79.7)$ & $3182(60.8)$ & $3910(42.8)$ & $2046(22.4)$ \\
\hline $\begin{array}{l}\text { People hesitate to take HIV test because reaction of other } \\
\text { people if positive (No) }\end{array}$ & $1376(26.3)$ & $963(18.4)$ & $2742(30.0)$ & $1018(11.1)$ \\
\hline People talk badly about people with or believed to have HIV (No) & $2357(45.0)$ & $1771(33.8)$ & $3814(41.7)$ & $1661(18.2)$ \\
\hline People with or believed to have HIV lose respect from other people (No) & $2598(49.7)$ & $1967(37.6)$ & $4044(44.3)$ & $1737(19.0)$ \\
\hline \multicolumn{5}{|l|}{ Risky Sexual Behavior Indicator } \\
\hline Had any STI in last 12 months (Yes) & $35(0.7)$ & $29(0.6)$ & $49(0.5)$ & $22(0.2)$ \\
\hline Had genital sore/ulcer in last 12 months (Yes) & $74(1.4)$ & $63(1.2)$ & $133(1.5)$ & $59(0.6)$ \\
\hline Had genital discharge in last 12 months (Yes) & $98(1.9)$ & $84(1.6)$ & $161(1.8)$ & $79(0.9)$ \\
\hline At least one sexual partner other than husband in last 12 months & $362(6.9)$ & $964(18.4)$ & $106(1.2)$ & $861(9.4)$ \\
\hline Had multiple life time sexual partner (Yes) & $1066(20.4)$ & $964(18.4)$ & $1579(17.3)$ & 861 (9.4) \\
\hline
\end{tabular}

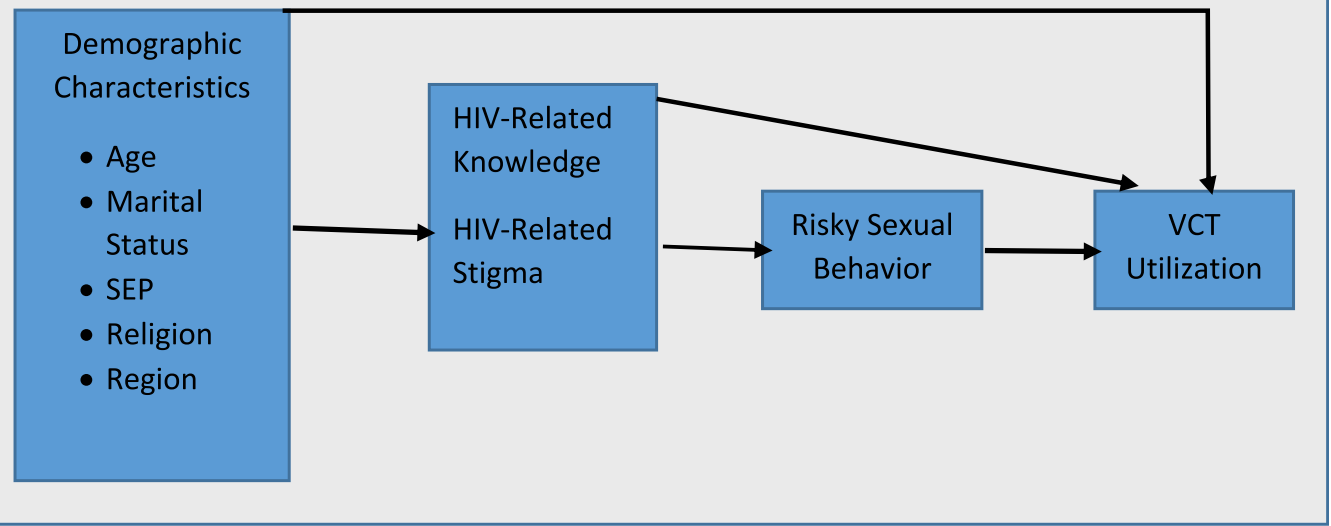

Fig. 2 conceptual and analytical framework for studying determinants of VCT utilization by women (both urban and rural residents) 
Table 2 Frequency distribution of VCT uptake among Women in Ethiopia in 2016 by urban-rural residence

\begin{tabular}{|c|c|c|c|c|c|c|}
\hline \multirow[t]{2}{*}{ Variables } & \multicolumn{3}{|l|}{ Urban } & \multicolumn{3}{|l|}{ Rural } \\
\hline & $\overline{N(\%)}$ & Ever HIV tested (\%) & $P$-value & $\overline{N(\%)}$ & Ever HIV tested (\%) & $P$-value \\
\hline \multicolumn{7}{|l|}{ Age in 5-year groups } \\
\hline $15-19$ & $1216(23.2)$ & 13.3 & $<0.001$ & $1996(21.8)$ & 13.9 & $<0.001$ \\
\hline $20-24$ & $1080(20.6)$ & 21.4 & & $1634(17.9)$ & 21.4 & \\
\hline $25-29$ & $982(18.8)$ & 22.5 & & $1629(17.8)$ & 20.6 & \\
\hline $30-34$ & $725(13.9)$ & 16.9 & & $1316(14.4)$ & 16.3 & \\
\hline $35-39$ & $572(10.9)$ & 12.5 & & $1159(12.7)$ & 13.1 & \\
\hline $40-44$ & $379(7.2)$ & 7.8 & & $804(8.8)$ & 9.3 & \\
\hline $45-49$ & $278(5.3)$ & 5.5 & & $599(6.6)$ & 5.5 & \\
\hline \multicolumn{7}{|l|}{ Marital Status } \\
\hline Never Married & $2125(40.6)$ & 30.2 & $<0.001$ & $1886(20.6)$ & 12.3 & $<0.001$ \\
\hline Ever Married & $3107(59.4)$ & 69.8 & & $7251(79.4)$ & 87.7 & \\
\hline \multicolumn{7}{|l|}{ Socio Economic Position } \\
\hline Low & $1699(32.5)$ & 28.9 & $<0.001$ & $8056(88.2)$ & 83.1 & $<0.001$ \\
\hline Middle & $2728(52.1)$ & 52.4 & & $985(10.8)$ & 14.8 & \\
\hline High & $805(15.4)$ & 18.6 & & $96(1.1)$ & 2.1 & \\
\hline \multicolumn{7}{|l|}{ Religion } \\
\hline Orthodox & $2989(57.1)$ & 61.1 & $<0.001$ & $3238(35.4)$ & 44.5 & $<0.001$ \\
\hline Catholic & $29(0.6)$ & 0.6 & & $55(0.6)$ & 0.5 & \\
\hline Protestant & $678(13)$ & 12.5 & & $1933(21.2)$ & 20.0 & \\
\hline Muslim & $1520(29.1)$ & 25.5 & & $3820(41.8)$ & 34.4 & \\
\hline Others & $16(0.3)$ & 0.3 & & $91(1)$ & 0.6 & \\
\hline \multicolumn{7}{|l|}{ Region } \\
\hline Tigray & $417(8)$ & 8.8 & $<0.001$ & $1239(13.6)$ & 20.0 & $<0.001$ \\
\hline Afar & $191(3.7)$ & 3.9 & & $831(9.1)$ & 5.9 & \\
\hline Amhara & $246(4.7)$ & 5.2 & & $1408(15.4)$ & 18.2 & \\
\hline Oromia & $249(4.8)$ & 4.2 & & $1426(15.6)$ & 11.9 & \\
\hline Somali & $271(5.2)$ & 2.8 & & $692(7.6)$ & 3.0 & \\
\hline Benishangul & $145(2.8)$ & 3.1 & & $864(9.5)$ & 9.9 & \\
\hline SNNPR & $225(4.3)$ & 4.1 & & $1547(16.9)$ & 16.8 & \\
\hline Gambela & $339(6.5)$ & 6.6 & & $555(6.1)$ & 7.9 & \\
\hline Harari & $511(9.8)$ & 10.4 & & $352(3.9)$ & 3.7 & \\
\hline Addis Adaba & $1815(34.7)$ & 34.9 & & $0(0)$ & 0.0 & \\
\hline Dire Dawa & $823(15.7)$ & 16.0 & & $223(2.4)$ & 2.8 & \\
\hline \multicolumn{7}{|l|}{ Knowledge Indicator } \\
\hline Low Knowledge & $4488(85.8)$ & 85.8 & 0.804 & $7362(80.6)$ & 80.7 & 0.003 \\
\hline High Knowledge & 725 (13.9) & 13.8 & & $1649(18.0)$ & 18.4 & \\
\hline Comprehensive Knowledge & $19(0.4)$ & 0.4 & & $126(1.4)$ & 0.9 & \\
\hline \multicolumn{7}{|l|}{ Stigma Indicator } \\
\hline High Stigma & $381(7.3)$ & 4.8 & $<0.001$ & $3037(33.2)$ & 26.6 & $<0.001$ \\
\hline Moderate Stigma & $2182(41.7)$ & 40.7 & & $3584(39.2)$ & 40.9 & \\
\hline Low Stigma & $2246(42.9)$ & 45.7 & & $2156(23.6)$ & 27.2 & \\
\hline No Stigma & $423(8.1)$ & 8.7 & & $360(3.9)$ & 5.3 & \\
\hline
\end{tabular}


Table 2 Frequency distribution of VCT uptake among Women in Ethiopia in 2016 by urban-rural residence (Continued)

\begin{tabular}{|c|c|c|c|c|c|c|}
\hline \multirow[t]{2}{*}{ Variables } & \multicolumn{3}{|l|}{ Urban } & \multicolumn{3}{|l|}{ Rural } \\
\hline & $N(\%)$ & Ever HIV tested (\%) & $P$-value & $N(\%)$ & Ever HIV tested (\%) & $P$-value \\
\hline \multicolumn{7}{|c|}{ Sexual Risky Behavior Indicator } \\
\hline High Risk & $294(5.6)$ & 6.9 & $<0.001$ & $191(2.1)$ & 2.7 & $<0.001$ \\
\hline Some Risk & $1020(19.5)$ & 23.9 & & $1631(17.9)$ & 22.9 & \\
\hline No Risk & $3918(74.9)$ & 69.2 & & $7315(80.1)$ & 74.3 & \\
\hline
\end{tabular}

\section{HIV/AIDS-related stigma}

Fear of loss of respect and others reaction if tested positive were measured parameters that indicated high stigma level among both urban and rural participants. The majority of rural participants said: children with HIV should not be allowed to attend school with children without HIV, they would be ashamed if someone in the family had HIV and they would not buy vegetables from vendor with HIV. Only $11.1 \%$ rural and $18.4 \%$ urban women who had fear of other's reaction if tested positive, had ever tested for HIV. Generally, women in rural had more stigmatizing attitude toward people living with HIV/AIDS (PLWHA) than those live in urban (Table 1). Eighteen point $6 \%(18.6 \%)$ urban and $2.1 \%$ rural women who had high stigmatizing attitude toward people living with HIV/AIDS (PLWHA) had been ever tested (Tables 2 \& 3).

\section{Risky sexual behavior history}

Having had multiple sexual partners was one of the most common risky sexual behavior observed among participants. Eighteen point $4 \%$ (18.4\%) urban and 9.4\% rural participants who had had multiple sexual partners had ever been tested (Table 1). Only 6.9\% of women in urban and $2.7 \%$ of rural women with high risky sexual behaviors had ever tested for HIV (Table 2).

\section{Factors associated with VCT utilization}

In the logistic regression analysis, utilization of VCT among women was positively associated with marital status (OR 4.79, 95\% CI: 3.92-5.86) in urban and (OR 3.46 , 95\% CI: 2.93-4.1) in rural. Similarly positive association was found between VCT utilization and socioeconomic positions (SEP) (OR 8.21, 95\%: 4.63-14.56) in rural (OR 3.32, 95\% CI: 2.52-4.38) in urban areas. Compared with 15-19 years of age, age less than 40 years in urban and less than 35 years in rural was strongly and positively associated (OR 2.3, 95\% CI: 1.7-3.13), (OR 1.43, 95\% CI: 1.19-1.73) respectively with VCT use. However, age $\geq 45$ and VCT utilization in rural area was found to be negatively associated (OR 0.71, 95\% CI: 0.57-0.9) compared with 15-19years of age. Being Muslim in urban and protestant in rural areas were found to be strongly and negatively associated (OR 0.68, 95\% CI: 0.56-0.83), (OR 0.73, 95\% CI:0.16-0.86) with
VCT utilization respectively. Negative associations was also found between VCT uptake in rural parts of different regions in the country (Tables 3 and 4). Similarly negative association (OR 0.36, 95\% CI: 0.25-0.52) in urban and (OR 0.4, 95\% CI:0.31-0.51) in rural was found between stigma and VCT uptake. Risky sexual behaviors was positively associated (OR 2.56, 95\% CI: 1.7-3.86) in urban and (OR 1.62, 95\% CI: 1.18-2.22) in rural with VCT uptake.

In model 1 where the association between the sociodemographic variables and VCT was assessed, age between 20 and 44, being married and having higher SEP ( $\geq$ middle) were associated with greater VCT use than being younger, never married and having lower SEP, respectively. Being Muslim in urban, protestant and older age $(\geq 45)$ in rural were the socio-demographic factors that were significantly and negatively associated with VCT utilization compared with orthodox and younger age respectively (Tables 3 and 4).

In model 2, both sociodemographic characteristics and more proximal determinants, HIV/AIDS-related knowledge and stigmatizing attitudes, were included into analysis. In this model, having stigmatizing attitude, having comprehensive knowledge and being protestant in rural stratum were negatively associated with VCT use compared with no stigma, low knowledge index and being orthodox respectively. Better SEP ( $\geq$ middle) and being married were positively associated with VCT utilization compared with lower SEP and being never married (Tables 3 and 4). In the full model at which all variables were included into analysis and risky sexual behavior was found to be an important predictor of VCT utilization. Being ever married, better SEP, having history of risky sexual behavior and age between 20 and 39 were found to be factors associated positively with VCT compared with those never married, lower SEP, no risky sexual behaviors and ages 15-19 respectively in the full model. Having stigmatizing attitude in both urban and rural and having comprehensive knowledge in rural area were negatively associated VCT in rural stratum in the full model (Tables 3 and 4).

\section{Discussion}

VCT service uptake among Ethiopian women (aged 1549 years) in this study is $52.9 \%$ and wide range of 
Table 3 Logistic regression analysis of determinants of VCT utilization among urban Women in Ethiopia, 2016

\begin{tabular}{|c|c|c|c|}
\hline \multirow[t]{2}{*}{ Variables } & \multicolumn{3}{|c|}{ Ever been tested for HIV } \\
\hline & Model 1 OR $(95 \% \mathrm{Cl})^{\mathrm{a}}$ & Model 2 OR(95\% CI) $)^{b}$ & Full Model OR(95\% Cl) \\
\hline \multicolumn{4}{|l|}{ Age (Ref: 15-17, 19, 20) } \\
\hline $20-24$ & $2.5(2.04-3.06)$ & $2.51(2.05-3.08)$ & $2.31(1.88-2.83)$ \\
\hline $25-29$ & $4.24(3.29-5.47)$ & $4.35(3.36-5.62)$ & $3.92(3.02-5.07)$ \\
\hline $30-34$ & $4.47(3.31-6.03)$ & $4.41(3.26-5.98)$ & $3.79(2.78-5.15)$ \\
\hline $35-39$ & $2.74(2.03-3.68)$ & $2.66(1.97-3.59)$ & $2.3(1.7-3.13)$ \\
\hline $40-44$ & $1.72(1.25-2.39)$ & $1.65(1.19-2.29)$ & $1.36(0.97-1.9)$ \\
\hline $45-49$ & $1.39(0.98-1.98)$ & $1.33(0.93-1.9)$ & $1.12(0.78-1.61)$ \\
\hline \multicolumn{4}{|c|}{ Marital Status (Ref: Never Married) } \\
\hline Ever Married & $4.81(3.95-5.85)$ & $5.01(4.11-6.12)$ & $4.79(3.92-5.86)$ \\
\hline \multicolumn{4}{|c|}{ Socioeconomic Position (Ref: Lower) } \\
\hline Middle & $2.14(1.81-2.53)$ & $2(1.69-2.37)$ & $1.94(1.64-2.3)$ \\
\hline High & $3.79(2.89-4.98)$ & $3.42(2.6-4.5)$ & $3.32(2.52-4.38)$ \\
\hline \multicolumn{4}{|l|}{ Religion (Ref: Orthodox) } \\
\hline Catholic & $0.64(0.23-1.77)$ & $0.73(0.27-2.02)$ & $0.79(0.28-2.2)$ \\
\hline Protestant & $0.75(0.59-0.96)$ & $0.8(0.63-1.03)$ & $0.85(0.66-1.09)$ \\
\hline Muslim & $0.63(0.52-0.76)$ & $0.64(0.53-0.77)$ & $0.68(0.56-0.83)$ \\
\hline Others & $0.28(0.09-0.85)$ & $0.34(0.11-1.04)$ & $0.39(0.13-1.2)$ \\
\hline \multicolumn{4}{|l|}{ Region (Ref: Tigray) } \\
\hline Afar & $1.02(0.63-1.65)$ & $0.98(0.6-1.59)$ & $0.96(0.59-1.57)$ \\
\hline Amhara & $0.89(0.57-1.39)$ & $0.82(0.52-1.29)$ & $0.82(0.52-1.29)$ \\
\hline Oromia & $0.38(0.25-0.57)$ & $0.36(0.23-0.54)$ & $0.38(0.25-0.57)$ \\
\hline Somali & $0.18(0.12-0.27)$ & $0.23(0.15-0.35)$ & $0.24(0.16-0.37)$ \\
\hline Benishangul & $1.2(0.7-2.07)$ & $1.09(0.63-1.88)$ & $1.14(0.66-1.98)$ \\
\hline SNNPR & $0.69(0.44-1.09)$ & $0.71(0.45-1.13)$ & $0.72(0.45-1.15)$ \\
\hline Gambela & $0.68(0.45-1.03)$ & $0.65(0.43-0.99)$ & $0.61(0.4-0.94)$ \\
\hline Harari & $1.01(0.70-1.46)$ & $0.94(0.65-1.37)$ & $1.01(0.69-1.47)$ \\
\hline Addis Adaba & $0.79(0.58-1.06)$ & $0.75(0.56-1.01)$ & $0.76(0.56-1.02)$ \\
\hline Dire Dawa & $0.99(0.70-1.38)$ & $0.86(0.61-1.21)$ & $0.88(0.62-1.25)$ \\
\hline \multicolumn{4}{|c|}{ HIV - Related Comprehensive Knowledge Index (Ref:Low) } \\
\hline High Knowledge & & $1.11(0.9-1.36)$ & $1.08(0.88-1.33)$ \\
\hline Comprehensive Knowledge & & $2.74(0.82-9.15)$ & $2.8(0.84-9.34)$ \\
\hline \multicolumn{4}{|l|}{ Stigma Indicator (Ref:No Stigma) } \\
\hline High Stigma & & $0.35(0.24-0.51)$ & $0.36(0.25-0.52)$ \\
\hline Moderate Stigma & & $0.82(0.61-1.09)$ & $0.83(0.62-1.11)$ \\
\hline Low Stigma & & $1.04(0.78-1.39)$ & $1.05(0.79-1.41)$ \\
\hline \multicolumn{4}{|c|}{ Sexual Risky Behaviour Indicator (Ref: No Risk) } \\
\hline High Risk & & & $2.56(1.7-3.86)$ \\
\hline Some Risk & & & $2.06(1.64-2.6)$ \\
\hline
\end{tabular}

Boldface entries were used to show $95 \% \mathrm{Cl}$ of the ratio doesn't contain 1, p-value is less than 0.05 and there are significant associations between the variables

difference was observed between women in urban and rural at VCT utilization. Age, marital status, socio economic positions, religion, regions, stigma, and risky sexual behaviors are important variables identified for VCT service uptake. Compared with other studies conducted in Ethiopia among men before 13 years and in 13 subSaharan Africa countries as well as in rural Tanzania on uptake of HIV voluntary counselling and testing services, 
Table 4 Logistic regression analysis of determinants of VCT utilization among rural Women in Ethiopia, 2016

\begin{tabular}{|c|c|c|c|}
\hline \multirow[t]{2}{*}{ Variables } & \multicolumn{3}{|c|}{ Ever been tested for HIV } \\
\hline & Model 1 OR(95\% CI) & Model 2 OR(95\% Cl) $)^{\mathrm{b}}$ & Full Model OR(95\% Cl) \\
\hline \multicolumn{4}{|l|}{ Age (Ref: 15-17, 19, 20) } \\
\hline $20-24$ & $1.75(1.48-2.07)$ & $1.75(1.47-2.07)$ & $1.72(1.45-2.04)$ \\
\hline $25-29$ & $1.54(1.29-1.84)$ & $1.52(1.28-1.82)$ & $1.49(1.24-1.78)$ \\
\hline $30-34$ & $1.47(1.22-1.77)$ & $1.5(1.25-1.81)$ & $1.43(1.19-1.73)$ \\
\hline $35-39$ & $1.14(0.94-1.38)$ & $1.15(0.95-1.4)$ & $1.09(0.89-1.32)$ \\
\hline $40-44$ & $1.18(0.96-1.45)$ & $1.19(0.97-1.47)$ & $1.11(0.9-1.37)$ \\
\hline $45-49$ & $0.78(0.62-0.98)$ & $0.78(0.62-0.98)$ & $0.71(0.57-0.9)$ \\
\hline \multicolumn{4}{|c|}{ Marital Status (Ref: Never Married) } \\
\hline Ever Married & $3.3(2.79-3.89)$ & $3.58(3.03-4.23)$ & $3.46(2.93-4.1)$ \\
\hline \multicolumn{4}{|c|}{ Socioeconomic Position (Ref: Lower) } \\
\hline Middle & $2.71(2.32-3.17)$ & $2.52(2.16-2.95)$ & $2.53(2.16-2.96)$ \\
\hline High & $9.5(5.37-16.81)$ & $8.34(4.7-14.79)$ & $8.21(4.63-14.56)$ \\
\hline \multicolumn{4}{|l|}{ Religion (Ref: Orthodox) } \\
\hline Catholic & $0.6(0.33-1.1)$ & $0.62(0.34-1.14)$ & $0.64(0.35-1.16)$ \\
\hline Protestant & $0.69(0.58-0.82)$ & $0.71(0.6-0.84)$ & $0.73(0.61-0.86)$ \\
\hline Muslim & $1.07(0.92-1.25)$ & $1.06(0.92-1.24)$ & $1.08(0.93-1.26)$ \\
\hline Others & $0.39(0.24-0.64)$ & $0.45(0.27-0.74)$ & $0.46(0.28-0.77)$ \\
\hline \multicolumn{4}{|l|}{ Region (Ref: Tigray) } \\
\hline Afar & $0.18(0.14-0.24)$ & $0.18(0.14-0.23)$ & $0.19(0.15-0.24)$ \\
\hline Amhara & $0.54(0.45-0.63)$ & $0.48(0.4-0.57)$ & $0.46(0.39-0.55)$ \\
\hline Oromia & $0.26(0.21-0.32)$ & $0.23(0.19-0.29)$ & $0.24(0.2-0.29)$ \\
\hline Somali & $0.1(0.07-0.13)$ & $0.11(0.08-0.14)$ & $0.11(0.08-0.15)$ \\
\hline Benishangul & $0.43(0.35-0.53)$ & $0.37(0.29-0.45)$ & $0.37(0.3-0.46)$ \\
\hline SNNPR & $0.55(0.45-0.68)$ & $0.53(0.43-0.65)$ & $0.55(0.44-0.67)$ \\
\hline Gambela & $0.86(0.67-1.11)$ & $0.7(0.55-0.91)$ & $0.69(0.54-0.89)$ \\
\hline Harari & $0.3(0.22-0.4)$ & $0.28(0.21-0.37)$ & $0.29(0.21-0.39)$ \\
\hline Dire Dawa & $0.48(0.34-0.67)$ & $0.39(0.28-0.55)$ & $0.41(0.29-0.58)$ \\
\hline \multicolumn{4}{|c|}{ HIV - Related Comprehensive Knowledge Index (Ref:Low) } \\
\hline High Knowledge & & $0.98(0.87-1.11)$ & $0.98(0.87-1.1)$ \\
\hline Comprehensive Knowledge & & $0.59(0.39-0.9)$ & $0.59(0.39-0.89)$ \\
\hline \multicolumn{4}{|l|}{ Stigma Indicator (Ref:No Stigma) } \\
\hline High Stigma & & $0.4(0.32-0.51)$ & $0.4(0.31-0.51)$ \\
\hline Moderate Stigma & & $0.6(0.47-0.76)$ & $0.59(0.47-0.75)$ \\
\hline Low Stigma & & $0.73(0.57-0.93)$ & $0.72(0.56-0.91)$ \\
\hline \multicolumn{4}{|c|}{ Sexual Risky Behavior Indicator (Ref: No Risk) } \\
\hline High Risk & & & $1.62(1.18-2.22)$ \\
\hline Some Risk & & & $1.35(1.19-1.53)$ \\
\hline
\end{tabular}

Boldface entries were used to show $95 \% \mathrm{Cl}$ of the ratio doesn't contain 1, p-value is less than 0.05 and there are significant associations between the variables

the prevalence of being tested for HIV in current study is higher $[16,18,20,21]$. This is due to efforts made in Ethiopia in the last years to integrate and expand VCT service. The initiation of affordable and effective medical care for people living with HIV/ADIS (PLWHA) might have also increased the demand of individuals for HIV testing. More importantly, the promotion of voluntary counseling and testing (VCT) by the government in the las two decades as one of the key policy responses to the HIV/AIDS epidemic, both as a primary prevention strategy and an entry point to other HIV/AIDS related services in the country has played a positive role for such 
improvement. However, the estimated prevalence of ever being tested for HIV in this study is still comparable with reports from four African countries (Nigeria, Mozambiqu, Kenya and Burkina Faso) [22-26].

Marriage is positively associated with VCT utilization in this study. Married women were found to utilize VCT better than those unmarried. This is consistent with the study done on factors affecting utilization of Voluntary HIV Counseling and Testing Services in Northwest Ethiopia [27]. This may probably be due to perceived personal risk about being infected with HIV in their past or current relationships.

HIV/AIDS related stigma and VCT uptake among women in Ethiopia was negatively and strongly associated in our study (OR 0.36, 95\% CI: 0.25-0.52, in urban and OR 0.4, 95\% CI:0.31-0.51, in rural). HIV/AIDS is the most stigmatized disease than any other health conditions and people living with HIV or the social groups to which they belong to have been suffering from stigmatization since the beginning of HIV epidemic. People living with HIV/AIDS (PLWHA) face not only personal medical problems but also social problems associated with the disease [28-30]. Therefore, due to fear of stigmatization women would not be willing to use VCT services. Many studies indicated that biomedical HIV prevention strategies, is predicated based on regular HIV testing [31-33]. However, anticipated stigma remains significant predictors of HIV testing behaviors hindering many people especially women from being tested and disclose their HIV status. Fear of stigma limits the efficacy of HIV-testing programs across subSaharan Africa, because in most villages everyone knows eventually who visited test sites [34-37]. The notions in the community that associate HIV with socially, morally and religiously unaccepted behavior [38], might also contributed for stigmatizing attitude and ultimately impose negative impact on VCT utilization among women in Ethiopia.

Consistent with the studies conducted in UK on migrants from five sub-Saharan African communities (Congo, Kenya, Uganda, Zambia, Zimbabwe) [39] and Burkina Faso [40], those who had history of high risky sexual behavior were more likely to utilize VCT in this study. Individuals with risky sexual behaviors lives under persistent fear and uncertainty about their own sero-status. They are usually suspicious and worries that they might have infected with HIV. This could have urged them to develop habits of seeking VCT service than individuals with less or no risky sexual behavior. Several other studies also reported increased HIV testing practice among individuals with risky sexual behaviors [41-43].

VCT utilization also significantly associates with religion in this study. One explanation is the dual role (positive and negative) religious view and practice might have when it comes to HIV/AIDS. Religious views could be challenges to communicate or educate about sexual health in religious communities and may become obstacle or barrier to VCT as well as other HIV preventions efforts (negative role). At the same time it might provide PLWHA spiritual well-being and social support (positive role), that could serve as facilitators to HIV treatment and care [44].

Muslim women in urban showed a low rate for VCT utilization than those from other religious and cultural backgrounds in this study and it's consistent with studies done in Ghana and Ethiopia [16, 45]. In Muslim cultures, sexuality is considered as private matter, a taboo topic for discussion and the social stigma attached to HIV/AIDS, that also exists in all societies is much more pronounced which prevents those at risk from coming forward for appropriate counseling, testing and treatment [46]. Social norms and ideas in Muslim communities, which associate HIV/AIDS with homosexuality, extramarital sex and drug use might have negatively affected VCT use among women [38]. Consistent with our study, being Muslim was found to be inversely associated with utilization of VCT in a cross-sectional survey conducted among men in Ethiopia [16]. Muslim women are less likely to use VCT services probably because of restricted role of women in Muslim community and therefore limiting their decisions to use VCT services.

In addition to religious factors, health extension program that has dramatically improved access to health and HIV prevention service in Ethiopia has stared recently in urban compared to rural area. This could be addition reason for low utilization of VCT service among urban Muslim women.

Protestant women in rural also showed low VCT uptake in this study. In Protestant community, there is a notions that HIV/AIDS comes due to promiscuity, homosexuality or as punishment from God for the sin (adultery) he/she did, contribute for such outcomes.

Women who ever married were significantly more likely to be tested for HIV than those who were never married in our study. This could result from compulsory counselling and testing promotion for couples intending to get married by different organizations including UNAIDS and religious groups. The perinatal HIV testing service available in most health institutions, might also contributed for high rate of testing among married women. Ethiopia Federal ministry of Health also encourages couples to learn about their HIV status and make informed decisions about their future that might have played positive role for married women to better utilize VCT. This suggest that the government and health organizations could play more positive role for all women not only for those going to marry, to better utilize VCT through such kinds of counselling and testing promotions. Similar positive association 
was reported in separate studies conducted in Kenya, Tanzania and Ethiopia [47-49].

Socio-economic position (SEP) was another important factor for VCT utilization among women in this study. An index of participants' socio-economic position was developed on the bases of their educational level, wealth index, and occupational status. Participants' in the middle and high SEP categories were more likely to be tested than those in low SEP. SEP encompasses not just income but also educational level, employment (financial security). SEP affect utilization of health services in many aspects including VCT service uptake, even in countries with universal health care system [50, 51]. Women at higher socio-economic positions have better educational level and economically privileged to seek and access health service, including VCT services than those at lower socioeconomic position. Hence, the government needs to make persistent advance in popular education, in increasing the individual income and decrease unemployment rate.

The cross-sectional nature of the data limits ability to draw casual inferences and using secondary source data like this is subjected to missing of important information (Variables) and recall bias are among the limitations of this study.

\section{Conclusion}

With the development of affordable and effective medical care for people living with HIV, the demand for HIV counselling and testing among women has rapidly increased in Ethiopia. However, in this study we found that stigmatizing attitude remains major factor, which is negatively affecting VCT uptake among women in Ethiopia. Concerted efforts should be made by all stakeholders to mitigate stigma, improve socio economic inequities and increase awareness on the benefit of VCT in controlling HIV in the society. In this aspect, the role of religious leader, schools, health extension workers and community leaders should not be undermined. Implementation and strengthening of alternative VCT services that include mobile VCT, routine offer of VCT at workplace, schools, religious congregations and home-based VCT service is highly recommended to increase uptake of VCT.

\section{Abbreviations \\ AIDS: Acquired Immune Deficiency Syndrome; CDC: Center for Disease Control and Prevention; DHS: The Demographic and Health Surveys; ECSA: The Ethiopian Central Statistical Agency; EDHS: Ethiopia Demographic and Health Survey; ICF: Strategic consulting \& communications for a digital world; PLWHA: People Living With HIV/AIDS; SEP: Socio-economic Position; SPSS: Statistical Package for the Social Sciences; STI: Sexually Transmitted Infections; UNAIDS: The joint United Nations program on HIV/AIDS: VCT: Voluntary Counselling and Testing}

\section{Acknowledgements}

We would like to express sincere thanks to MEASURE DHS for allowing us access to the 2016 EDHS dataset. Many thanks also go to all the respondents who participated in the survey.

\section{Authors' contributions}

Conceptualization, ANE and PL; Methodology, ANE; GS and PL; Formal Analysis, ANE and PL; Data Curation, ANE; Writing-Original Draft Preparation, ANE; Writing-Review \& Editing, ANE; GS and PL. All authors have seen and approved the submission of this manuscript.

\section{Funding}

The authors declare no fund received for this work.

\section{Availability of data and materials}

The data is available on https://dhsprogram.com/Data/. To request dataset access, one must first register as a DHS data user on DHS website. Dataset access is only granted for legitimate research purposes. Dataset requests must include contact information, a research project title, and a description of the analysis one propose to perform with the data.

\section{Ethics approval and consent to participate}

All DHS surveys are approved by ICF International as well as an institutional review board (IRB) in the host country to make sure that the protocols are in compliance with the U.S. Department of Health and Human Services regulations for the protection of human subjects. The 2016 Ethiopia DHS was reviewed and approved by the National Research Ethics Review Committee of the Ministry of Science and Technology in Ethiopia and also by the Institutional Review Board of ICF, in the United States. Participants gave informed verbal consent before taking part in the survey and the procedure for verbal consent was approved by National Research Ethics Review Committee of the Ministry of Science and Technology in Ethiopia and Institutional Review Board of ICF, in the United States. Before each interview, an informed consent statement is read to the respondent, who may accept or decline to participate. The DHS informed consent statement emphasizes participation is voluntary; that the respondent may refuse to answer any question, or terminate participation at any time; and that the respondent's identity and information will be kept strictly confidential. Consent for publication was obtained from MEASURE DHS. The DHS Program is authorized to distribute, at no cost, unrestricted survey data files for legitimate academic research.

\section{Consent for publication}

Not applicable.

\section{Competing interests}

The authors declare that they have no competing interests.

Received: 12 October 2018 Accepted: 11 December 2019 Published online: 21 December 2019

\section{References}

1. Sculier D, Calmy A. What's new in HIV in 2014? Rev Med Suisse. 2015: 11(456-457):148-52 PubMed PMID: 25799673. Epub 2015/03/25. VIH: l'annee 2014 en revue. fre.

2. Zhang L, Gui X, Wang B, Ji H, Yisilafu R, Li F, et al. A study of immunoprophylaxis failure and risk factors of hepatitis B virus mother-toinfant transmission. Eur J Pediatr. 2014;173(9):1161-8 PubMed PMID: 24699981. Epub 2014/04/05. eng.

3. Owen SM. Testing for acute HIV infection: implications for treatment as prevention. Curr Opin HIV AIDS. 2012;7(2):125-30 PubMed PMID: 22314506. Epub 2012/02/09. eng.

4. Yawson AE, Dako-Gyeke P, Addo SA, Dornoo BT, Addo NA. Utilization of HIV testing and counseling in Ghana: implications for universal coverage. Afr J Reprod Health. 2014;18(1):144-54 PubMed PMID: 24796179. Epub 2014/05/ 07. eng.

5. Armstrong WS, Taege AJ. HIV screening for all: the new standard of care. Cleve Clin J Med. 2007;74(4):297-301 PubMed PMID: 17438679. Epub 2007/ 04/19. eng.

6. Janssen RS. Implementing HIV screening. Clin Infect Dis. 2007;45(Suppl 4): S226-31 PubMed PMID: 18190291. Epub 2008/02/08. eng.

7. Laurent C. Commentary: HIV testing in low- and middle-income countries: an urgent need for scaling up. J Public Health Policy. 2013;34(1):17-21 PubMed PMID: 23235557. Epub 2012/12/14. eng.

8. Eba PM, Lim H. Reviewing independent access to HIV testing, counselling and treatment for adolescents in HIV-specific laws in sub-Saharan Africa: 
implications for the HIV response. J Int AIDS Soc. 2017;20(1):21456 08/11/08/ 23/received 07/22/accepted. PubMed PMID: PMC5577701.

9. Sidibé M, Loures L, Samb B. The UNAIDS 90-90-90 target: a clear choice for ending AIDS and for sustainable health and development. J Int AIDS Soc. 2016;19(1):21133 07/15/04/04/received 06/21/revised 07/03/accepted. PubMed PMID: PMC4947868.

10. Jamieson D, Kellerman SE. The 909090 strategy to end the HIV Pandemic by 2030: Can the supply chain handle it? J Int AIDS Soc. 2016;19(1):20917 06/30/ 01/15/received 05/12/revised 05/31/accepted. PubMed PMID: PMC4930545.

11. Bain LE, Nkoke C, Noubiap JJN. UNAIDS 90-90-90 targets to end the AIDS epidemic by 2020 are not realistic: comment on "Can the UNAIDS 90-9090 target be achieved? A systematic analysis of national HIV treatment cascades". BMJ Global Health. 2017;2(2):e000227.

12. Asaolu IO, Gunn JK, Center KE, Koss MP, Iwelunmor JI, Ehiri JE. Predictors of HIV testing among youth in sub-Saharan Africa: a cross-sectional study. PLoS One. 2016;11(10):e0164052 PubMed PMID: 27706252. Pubmed Central PMCID: PMC5051677. Epub 2016/10/06. eng.

13. Rosenberg NE, Westreich D, Barnighausen T, Miller WC, Behets F, Maman S, et al. Assessing the effect of HIV counselling and testing on HIV acquisition among South African youth. AIDS. 2013;27(17):2765-73 PubMed PMID: 23887069. Pubmed Central PMCID: PMC4028633. Epub 2013/07/28. eng.

14. Kurth AE, Lally MA, Choko AT, Inwani IW, Fortenberry JD. HIV testing and linkage to services for youth. J Int AIDS Soc. 2015;18(2 Suppl 1):19433 PubMed PMID: 25724506. Pubmed Central PMCID: PMC4344538. Epub 2015/03/01. eng.

15. Kharsany ABM, Karim QA. HIV infection and AIDS in sub-Saharan Africa: current status, challenges and opportunities. Open AIDS J. 2016;10:34-48 PubMed PMID: 27347270.

16. Leta TH, Sandøy IF, Fylkesnes K. Factors affecting voluntary HIV counselling and testing among men in Ethiopia: a cross-sectional survey. BMC Public Health. 2012;12(1):438 2012/06/15.

17. Teklehaimanot HD, Teklehaimanot A, Yohannes M, Biratu D. Factors influencing the uptake of voluntary HIV counseling and testing in rural Ethiopia: a cross sectional study. BMC Public Health. 2016;16:239 03/08/08/ 20/received 03/01/accepted. PubMed PMID: PMC4784416.

18. Ide C, Simon C, Garnett GP, Simon G. Patterns of uptake of HIV testing in sub-Saharan Africa in the pre-treatment era. Tropical Med Int Health. 2012; 17(8):e26-37.

19. Central Statistical Agency - CSA/Ethiopia, ICF. Ethiopia Demographic and Health Sruvey 2016. Addis Ababa: CSA and ICF; 2017.

20. Cremin I, Cauchemez S, Garnett Geoffrey P, Gregson S. Patterns of uptake of HIV testing in sub-Saharan Africa in the pre-treatment era. Trop Med Int Health. 2012;17(8):e26-37 2012/08/01.

21. Wringe A, Isingo R, Urassa M, Maiseli G, Manyalla R, Changalucha J, et al. Uptake of HIV voluntary counselling and testing services in rural Tanzania: implications for effective HIV prevention and equitable access to treatment. Trop Med Int Health. 2008;13(3):319-27 PubMed PMID: 18397395. Epub 2008/04/10. eng.

22. Aniebue $P$, Aniebue U. Voluntary counseling and willingness to screen among Nigerian long distance truck drivers. Niger Med J. 2011;52(1):49-54.

23. Paulin HN, Blevins M, Koethe JR, Hinton N, Vaz LM, Vergara AE, et al. HIV testing service awareness and service uptake among female heads of household in rural Mozambique: results from a province-wide survey. BMC Public Health. 2015;15(1):132.

24. Onyeonoro U, Emelumadu O, Chuku A, Kanu O, Ebenebe U, Onwukwe N, et al. Knowledge and utilization of HIV counseling and testing services among students of a tertiary institution in Abia State, South East Nigeria. J HIV Hum Reprod. 2014;2(1):8-14 January 1, 2014.

25. Achia TNO, Obayo E. Trends and correlates of HIV testing amongst women: lessons learnt from Kenya. Afr J Prim Health Care Fam Med. 2013;5(1):547 09/27/05/01/received 06/29/accepted. PubMed PMID: PMC4502880.

26. Kirakoya-Samadoulougou F, Jean K, Maheu-Giroux M. Uptake of HIV testing in Burkina Faso: an assessment of individual and community-level determinants. BMC Public Health. 2017;17:486 05/22/05/02/received 05/12/ accepted. PubMed PMID: PMC5441086.

27. Desta WG, Sinishaw MA, Bizuneh KD. Factors Affecting Utilization of Voluntary HIV Counseling and Testing Services among Teachers in Awi Zone, Northwest Ethiopia. AIDS Res Treat. 2017;2017:9034282 PubMed PMID: 28512582. Epub 04/23. eng.

28. Deacon H, Boulle A. Commentary: factors affecting HIV/AIDS-related stigma and discrimination by medical professionals. Int J Epidemiol. 2007;36(1):185-6.
29. Dahlui M, Azahar N, Bulgiba A, Zaki R, Oche OM, Adekunjo FO, et al. HIV/ AIDS Related Stigma and Discrimination against PLWHA in Nigerian Population. PloS one. 2015;10(12):e0143749 12/10/05/31/received 11/08/ accepted. PubMed PMID: PMC4675522.

30. Wingood GM, Reddy P, Peterson SH, DiClemente RJ, Nogoduka C, Braxton $\mathrm{N}$, et al. HIV stigma and mental health status among women living with HIV in the Western cape, South Africa. S Afr J Sci. 2008; 104:237-40.

31. Golub SA, Gamarel KE. The Impact of Anticipated HIV Stigma on Delays in HIV Testing Behaviors: Findings from a Community-Based Sample of Men Who Have Sex with Men and Transgender Women in New York City. AIDS Patient Care STDS. 2013;27(11):621-7 PubMed PMID: PMC3820140.

32. Elsheikh IE, Crutzen R, Van den Borne HW. Perceptions of Sudanese women of reproductive age toward HIV/AIDS and services for Prevention of Mother-to-Child Transmission of HIV. BMC Public Health. 2015;15(1):674 2015/07/17.

33. Gamarel KE, Nelson KM, Stephenson R, Santiago Rivera OJ, Chiaramonte D, Miller RL. Anticipated HIV stigma and delays in regular HIV testing behaviors among sexually-active young gay, bisexual, and other men who have sex with men and transgender women. AIDS Behav. 2018; 22(2):522-30,

34. Bekalu MA, Eggermont S, Ramanadhan S, Viswanath K. Effect of media use on HIV-related stigma in sub-Saharan Africa: a cross-sectional study. PLoS One. 2014;9(6):e100467.

35. Rankin WW, Brennan S, Schell E, Laviwa J, Rankin SH. The stigma of being HIV-positive in Africa. PLoS Med. 2005;2(8):e247.

36. Tsai AC, Bangsberg DR, Weiser SD. Harnessing poverty alleviation to reduce the stigma of HIV in sub-Saharan Africa. PLoS Med. 2013;10(11):e1001557.

37. Koku EF. HIV-related stigma among African immigrants living with HIV/AIDS in USA. Sociol Res Online. 2010;15(3):5.

38. Remien RH, Chowdhury J, Mokhbat JE, Soliman C, Adawy ME, El-Sadr W. Gender and care: access to HIV testing, care, and treatment. J Acquir Immune Defic Syndr. 2009:51(Suppl 3):S106-S10 PubMed PMID: 19553777. eng.

39. Fenton KA, Chinouya M, Davidson O, Copas A. HIV testing and high risk sexual behaviour among London's migrant African communities: a participatory research study. Sex Transm Infect. 2002;78(4):241-5.

40. Kirakoya-Samadoulougou F, Yaro S, Deccache A, Fao P, Defer M-C, Meda N, et al. Voluntary HIV testing and risky sexual behaviours among health care workers: a survey in rural and urban Burkina Faso. BMC Public Health. 2013;13:540 06/05/11/12/received 03/11/accepted. PubMed PMID: PMC3718644.

41. Adebayo OW, Gonzalez-Guarda RM. Factors Associated With HIV Testing in Youth in the United States: An Integrative Review. J Assoc Nurses AIDS Care. 2017;28(3):342-62 2017/05/01.

42. Samet JH, Winter MR, Grant L, Hingson R. Factors associated with HIV testing among sexually active adolescents: a Massachusetts survey. Pediatrics. 1997;100(3):371-7.

43. Renzi C, Zantedeschi E, Signorelli C, Osborn JF. Factors associated with HIV testing: results from an Italian General Population Survey. Prev Med. 2001; 32(1):40-8 2001/01. PubMed PMID: 11162325. eng.

44. Medved KH. Are religion and spirituality barriers or facilitators to treatment for HIV: a systematic review of the literature. AIDS Care. 2017;29(1):1-13 2017/01/02

45. Gyapong R, Addy BS, Buabeng KO, Bray E, Cobbinah-Abraham V. Educational status and religion influence uptake of voluntary HIV counseling and testing by Ghanaian antenatal clinic attendees; 2014. p. 30-8.

46. Hasnain M. Cultural Approach to HIV/AIDS Harm Reduction in Muslim Countries. Harm Reduction J. 2005;2:23 10/27/11/30/received 10/27/ accepted. PubMed PMID: PMC1298319.

47. Desta WG, Sinishaw MA, Bizuneh KD. Factors affecting utilization of voluntary HIV counseling and testing services among teachers in Awi zone, Northwest Ethiopia. AIDS Res Treat. 2017;2017:9.

48. Wangui JK, Kikuvi GM, Msanzu JB. Factors influencing utilization of Voluntary Counseling and Testing Services among Kenya Ports Authority employees in Mombasa, Kenya. Glob J Health Sci. 2016;1 (1):27-41 2016-09-26.

49. Mossdorf E, Stoeckle M, Vincenz A, Mwaigomole Emmanuel G, Chiweka E, Kibatala P, et al. Impact of a national HIV voluntary counselling and testing (VCT) campaign on VCT in a rural hospital in Tanzania. Tropical Med Int Health. 2010;15(5):567-73. 
50. Filc D, Davidovich N, Novack L, Balicer RD. Is socioeconomic status associated with utilization of health care services in a single-payer universal health care system? International Journal for Equity in Health. 2014;13:115 11/28/04/11/received 11/10/accepted. PubMed PMID: PMC4260253.

51. Nunes BP, Thumé E, Tomasi E, Duro SMS, Facchini LA. Socioeconomic inequalities in the access to and quality of health care services. Rev Saude Publica. 2014;48:968-76.

\section{Publisher's Note}

Springer Nature remains neutral with regard to jurisdictional claims in published maps and institutional affiliations.

- fast, convenient online submission

- thorough peer review by experienced researchers in your field

- rapid publication on acceptance

- support for research data, including large and complex data types

- gold Open Access which fosters wider collaboration and increased citations

- maximum visibility for your research: over $100 \mathrm{M}$ website views per year

At BMC, research is always in progress. 